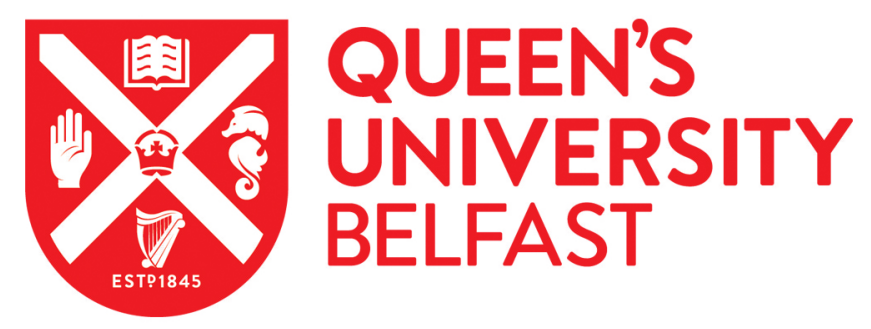

\title{
Exploring lay views on physical activity and their implications for public health policy. A case study from East Belfast
}

Prior, L., Scott, D., Hunter, R., Donnelly, M., Tully, M. A., Cupples, M. E., \& Kee, F. (2014). Exploring lay views on physical activity and their implications for public health policy. A case study from East Belfast. Social Science \& Medicine, 114C, 73-80. https://doi.org/10.1016/j.socscimed.2014.05.015

Published in:

Social Science \& Medicine

Document Version:

Early version, also known as pre-print

Queen's University Belfast - Research Portal:

Link to publication record in Queen's University Belfast Research Portal

\section{General rights}

Copyright for the publications made accessible via the Queen's University Belfast Research Portal is retained by the author(s) and / or other copyright owners and it is a condition of accessing these publications that users recognise and abide by the legal requirements associated with these rights.

Take down policy

The Research Portal is Queen's institutional repository that provides access to Queen's research output. Every effort has been made to ensure that content in the Research Portal does not infringe any person's rights, or applicable UK laws. If you discover content in the Research Portal that you believe breaches copyright or violates any law, please contact openaccess@qub.ac.uk. 


\section{Elsevier Editorial System(tm) for Social Science \& Medicine Manuscript Draft}

Manuscript Number: SSM-D-13-02865R2

Title: Exploring lay views on physical activity and their implications for public health policy. A case study from East Belfast.

Article Type: Article

Keywords: Health in all policy; Health promotion; Physical activity; Social ecology; Sport; Therapeutic landscapes; Urban regeneration.

Corresponding Author: Prof. Lindsay Prior, PhD

Corresponding Author's Institution: QUB

First Author: Lindsay Prior, PhD

Order of Authors: Lindsay Prior, PhD; David Scott, PhD; Ruth Hunter, PhD; Michael Donnelly, PhD; Mark Tully, PhD; Margaret Cupples, MD; Frank Kee, MD

Manuscript Region of Origin: UNITED KINGDOM

Abstract: It is now recognised that inactive lifestyles underpin much of the disease burden evident in the richer nations of the world. Indeed, the WHO has identified physical inactivity as a 'global public health problem' and has established minimum physical activity (PA) targets for people at different stages of the life-course. Yet, according to WHO, just under $1 / 3$ of working age adults across the globe meet those targets and it is not at all clear how the disjunction between the recommendations of policy makers and the behaviour of ordinary people might be surmounted.

Using an opportunity to examine the impact of an urban regeneration project on community residents in East Belfast (Northern Ireland) this paper examines the views of some 113 people on how to increase rates of PA in an area of multiple deprivation. The results of the analysis suggest that lay people rarely consider PA as a discrete issue, or one that centres on individuals and their motivation, but rather as one component in a complex web of concerns, processes and events that include such things as the actions of neighbours and relatives, material and political environments, vandalism, violence, and the weather. We explore and unravel the nature of those concerns using novel methods of content analysis that generate 'issue webs'. Particular attention is paid to the ways in which lay people conceptualize 'activity' and to the manner in which they point to ways of encouraging activity that are rooted in everyday life rather than in the corpocentric, agent-centred, and sport dominated strategies favoured by local policy makers. Our results support those who argue that interventions to increase rates of PA need to move beyond behavioural approaches that focus on individuals and consider the social, political and material contexts in which 'activity' occurs. 
Research Highlights.

- Challenges the dominance of behavioural approaches to public health interventions.

- Supports a social ecology perspective on policy relating to physical activity.

- Introduces the notion of 'issue webs' as a focus for qualitative research.

- Explores the complexity of public health problems in a conflict zone. 
Title: Exploring lay views on physical activity and their implications for public health policy. A case study from East Belfast.

\section{Authors:}

Prior, L $^{1}$, Scott, D. ${ }^{2}$, Hunter, R. ${ }^{2}$, Donnelly, M. ${ }^{2}$, Tully, M, A., ${ }^{2}$, Cupples, M. E. ${ }^{2}$. Kee, F. ${ }^{2}$.

${ }^{1}$ UKCRC Center of Excellence for Public Health Research (Northern Ireland), \& School of Sociology \& Social Policy \& Centre of Excellence in Public Health, Queen's University, Belfast, BT7 1NN. UK.

2. UKCRC Center of Excellence for Public Health Research (Northern Ireland), Institute of Clinical Sciences, Block B, Queens University Belfast, Royal Victoria Hospital, Grosvenor Road, Belfast BT12 6BA. UK.

\section{Corresponding Author:}

Prof. Lindsay Prior, School of Sociology \& Social Policy \& Centre of Excellence in Public Health Queen's University, Belfast, BT7 1NN. UK.

Tel: +44(0) 2890973236 Fax: +44(0)2890973943 E-Mail: (I.prior@qub.ac.uk)

\section{E-Mail addresses of other contributing authors:}

David Scott, (David.Scott@qub.ac.uk), Ruth Hunter, (ruth.hunter@qub.ac.uk), Michael Donnelly, (michael.donnelly@qub.ac.uk), Mark Tully, (m.tully@qub.ac.uk), Margaret Cupples (m.cupples@qub.ac.uk), Frank Kee, (F.Kee@qub.ac.uk)

\section{Acknowledgements:}

The study on which this work is based (the PARC study) is supported by a grant from the National Prevention Research Initiative (grant number G0802045). The Funding Partners are: Alzheimer's Research Trust; Alzheimer's Society; Biotechnology and Biological Sciences Research Council; British Heart Foundation; Cancer Research UK; Chief Scientist Office, Scottish Government Health Directorate; Department of Health; Diabetes UK; Economic and Social Research Council; Engineering and Physical Sciences Research Council; Health and Social Care Research and Development Division of the Public Health Agency (HSC R\&D Division); Medical Research Council; The Stroke Association; Welsh Assembly Government and World Cancer Research Fund. We also wish to acknowledge funding from the Department for Employment and Learning, Northern Ireland (grant number M6003CPH) and the UKCRC Centre of Excellence for Public Health Northern Ireland. 


\section{Getting folks active.}

It is now recognised that inactive lifestyles underpin much of the disease burden evident in the richer nations of the world. Indeed, the WHO has identified physical inactivity as a 'global public health problem' and has established minimum physical activity (PA) targets for individuals at different stages of the life-course. Yet, according to the WHO Global Data Base (2013), just under $1 / 3$ of working age adults across the globe meet those targets and it is not at all clear how the disjunction between the recommendations of policy makers and the behaviour of the majority of individuals might be surmounted. A key aim of this paper is to show how a policy rooted in the understandings of lay people about the nature and role of PA in everyday life might help to overcome the discontinuity.

In the wake of the aforementioned gap between policy and behaviour there has been a push to design suitable interventions to encourage individuals to meet the required PA targets (see, for example, National Institute for Health and Clinical Excellence, 2006). In a large number of cases the design of the intervention has been structured in accordance with explanatory models of health behaviour that are predominantly individualistic and psychological (see, King, Stokols, Talen et al, 2002), such as the health belief model (e.g. Becker, 1974), the theory of planned behaviour (e.g. Ajzen, 1991), and social learning theory (Bandura, 1991). Indeed, Glanz, Rimer, and Viswanath (2008) suggested that the most frequently cited theories and models of health behaviour appearing in health promotion studies between 2000-2005 were the health belief model, together with social cognitive theory and stages of change model. Many of these models have been criticised for underestimating the influence of social, political and cultural influences on physical activity (PA) (see, Burke, Joseph, Pasick and Barker, 2009), and we would argue that whatever their strengths, they mostly fail to either connect with or reflect lay ideas 
about the role and nature of such activity in everyday life. Yet lay views of the world can offer excellent starting points for the design of population based health initiatives and a key objective of this paper is to show how the talk of ordinary people about the nature of PA can contribute to an enhanced comprehension, theorization and practical resolution of relevant public health issues.

The paper is based on an analysis of the ways in which community residents in East Belfast (Northern Ireland) talk about the use and potential use of a $9 \mathrm{~km}$ linear park currently being re-designed and re-developed as a component of an urban regeneration project. The new design includes provision for additional cycle paths, walkways and other infrastructure, and a key objective of the wider regeneration scheme is to 'provide opportunities for improving health and wellbeing' (See, http://www.communitygreenway.co.uk/). In line with current UK policies for public involvement in research we sought the views of community residents via a variety of ways. The latter included one-to-one interviews with community leaders and potential users of the park, a random survey of 1209 residents who were interviewed about current activities, attitudes and opinions about the park, and focus group $(\mathrm{N}=14)$ discussions with a wide cross-section of people $(\mathrm{N}=113)$ in community based organizations (the research protocol is available in Tully, Hunter, McAneney et al, 2013). What follows centres on our findings from the focus group discussions.

Although the residents of the intervention area were approached without any theoretical pre-conceptions as to what influenced health behaviour and PA, we found that lay thinking about health and wellbeing and the role of activity resonated particularly strongly with many assumptions of a social ecology perspective on health promotion (Ding, Sallis, Conway et al, 2012; Sallis and Owen, 1997; Stokols, 1992). That was especially so in so far as our 
respondents focussed attention on structures (material, social, cultural and political) and processes more than on personal motives or motivation; and on groups and communities rather than individuals. In so doing they offered conceptualizations of 'activity' much wider than those found in many health policy documents. Above all, by positioning physical activity in a web of issues and concerns our respondents point to ways of encouraging activity that are rooted in everyday life rather than in the corpocentric, agent centred and often sport dominated strategies favoured by policy makers.

\section{Background, context and methods of study.}

A central feature of what has been called the epidemiological transition is that a "longterm shift occurs in mortality and disease patterns whereby pandemics of infection are gradually displaced by degenerative and man-made diseases as the chief form of morbidity and primary cause of death" (Omran, 1971:513). One of the consequences of such a transition is that the health policies of rich nations have encompassed a concern to promote 'healthy lifestyles' so as to reduce mortality and morbidity rates across the life-course. Indeed, changing behaviour and encouraging individuals to adopt healthy lifestyles has figured as an aim of global, national and local health policy for some decades (e.g. WHO, 2010; UK Department of Health, 2011a). Many lifestyle targets have been set. In terms of physical activity, for example, the policy recommendation is that working age adults be physically active for at least 150 minutes per week (WHO, 2010; UK Department of Health, 2011b). Yet, only a minority of people meet the suggested targets and country specific surveys indicate that such factors as age, gender, and ethnic and economic background are strongly associated with inactivity (e.g. SAPAS, 2010). Our aim was to investigate how those factors might impact on rates of PA in the context of an urban regeneration programme extending across areas of both deprivation and relative affluence. 
The 'community greenway' regeneration project [henceforth CCG] referred to in our introduction is best envisaged as a $9 \mathrm{~km}$ purposefully designed linear park that winds its way along a river course from the inner city of Belfast through to its eastern and generally more affluent suburbs. The website for the greenway project states that the CCG, "will provide immediate benefit to the 40,000 people living in the wards adjacent to the river. Specifically, it will directly improve the living environment, reinstating a valuable amenity for local people and provide opportunities for improving health and well being. The Project will act as a catalyst for physical and economic development and improve access and connections for local communities to open spaces." (See, CCG, 2013). As well as providing an insight into the connections that lay people make between green space, health and wellbeing, our analysis also provides an assessment of the likelihood of such claims being realized.

The inner city wards of East Belfast are classified as among some of the most deprived in Northern Ireland, (NISRA, 2010). Whilst much of the housing is modern, the wider urban infrastructure is redolent of an industrial past. Redundant shipyard gantries dominate the skyline, and few residents now work in manufacturing industry. Levels of education and training are low whilst levels of unemployment are relatively high. In addition, Belfast as a city has been a site of considerable political, military and social conflict during the last four to five decades and the CCG wards adjacent to the commercial centre of the city are still subject to inter-communal tension and violence. Symbols of sectarian strife are prominent in the area - often in the form of wall paintings that laud the behaviour of the paramilitary groups that hold sway in working class communities (for an example, see Figure 1).

As indicated, the data that we present here were gathered from 14 separate focus groups containing 113 individuals. Participants were recruited from a wide range of community 
associations during the winter of 2010-2011, and ethical approval for the study was provided by OREC, Northern Ireland, (Reference, 09/NIR02/66). Our respondents included parents ( $\mathrm{N}=20$ in 3 groups), members of a recovering mental health group for men $(\mathrm{N}=8)$, a group of teenage girls on an outdoor award scheme $(\mathrm{N}=10)$, a group of community activists $(\mathrm{N}=7)$ and a group of over $65 \mathrm{~s}(\mathrm{~N}=13)$. The information sheet that was given to the participants stated that, "The researchers and the Public Health Agency want to find out more about your views about how greater levels of physical activity might be promoted in the local population through the use of more open and green spaces that will be developed as part of the [CCG]". And in the course of offering their views, participants spoke about the existing nature of the parkland area, its current use, its likely use and the factors that might facilitate or impede such use both for the community as a whole and for the individuals who engaged in the discussions.

Our main aim was to identify the key factors that residents pointed to as impediments or facilitators to the use of existing infrastructure for physical activity, and the factors they pointed to as likely to promote or impede use of the on-stream infrastructure for such activity. The analyses of the focus group data were undertaken via a series of steps. First, the verbatim transcripts were read (a number of times) so as to a gain a general sense of what was being discussed. Transcripts were then scrutinised via use of a concordance package and the most frequently used words used (in context) by the participants (and not the moderator) throughout the entire session were identified. The process led to the construction of a series of simple 'codes' or code words - such as 'walking' and 'running' (for activities); 'safety' and 'summer' (for facilitators); and 'traffic' and 'vandalism' (for impediments) - by means of which focus group talk could be organized and analyzed. In a number of cases no single word in the transcript could cover the diverse nature of the objects or processes referred to, and in such cases a second 
order or researcher concept was introduced. For example, respondents variously referred to seats and benches, toilets, cafes, water fountains, lights and lighting as things that could encourage people to 'get out and about' - these things were conceptualized and coded under 'physical infrastructure'. In like manner there were numerous references to people who were notably territorial in their attitude to space - rowdy young men in specific areas of parks and open ground; or residents who covered their streets in sectarian symbolism (see Fig.1.) and made the area unwelcome to people in neighbouring wards - such references were conceptualized as 'Territoriality'.

Having established a list of codes, these were then used on the transcripts to categorize what was being discussed in each turn of a speaker's contribution. During analysis our attention was centred not simply on how many times a given item or element was referred to in speech, but also on how the codes were co-associated in the talk of the participants - that is, on how things were linked. Using novel methods of content analysis (Prior, 2014), the results can be visualized in what we refer to as 'issue webs'. An example of one such web for a single focus group - group 12 - is provided in Figure 2. The diagram has been drawn with the aid of the social network analysis programme Pajek (de Nooy, Mrvar, Batgelj, 2005). The size of the nodes in Fig. 2 are proportional to the number of references to the code made by the participants (excluding the moderator). A square root function has been used to transform the data so as to manage the wide disparity in the number of references to, say, 'walking' as against 'summer' and to render the web more readable (so raw differences in node size can be considerable). The thickness of the arcs (or lines) between the nodes is proportional to the strength of the coassociation between codes. 
Inevitably members of each focus group tended to reference slightly different things in their conversations - say, swimming in one group and gardening in another; or the weather in one and summer and winter in another. To accommodate these variations and to incorporate the data contained in all 14 groups into a common frame a slightly different analytical strategy was used from that above. Therein only second order constructs were applied to the available text. The unit of analysis was each speaker's turn (rather than number of individual references to walking, running, safety, etc). Again, we sought to identify only those things that were said to facilitate or impede either physical activity, or simply being out and about. For example a speaker might report (at some length) that to encourage use of the greenway for casual walking (often referred to as 'dandering' or a 'wee dander') through parks and open spaces the provision of seats and seating is required as well as a 'wee café' and shelter against bad weather. This would be coded as 1 reference to physical infrastructure (co-associated to being out and about) for that turn. The results of the analysis are available in Figure 3. The issue web in Figure 3 enables us to see not merely what kinds of issues were raised, but the relative frequency with which they were raised and the relative strength of association between one factor and another. Once again we have used a square root transformation in order to manage the wide range of frequencies with which the various issues arose in focus group talk. The thickness of the arcs or lines reflect a measure of co-association between coded items. In contrast to more common forms of data analysis such as, say, thematic analysis (Braun \& Clarke, 2006; Bryman, 2008) our method enables the reader to get a clear sense of the relative importance of any given issue in a wider context, and how strongly or weakly that issue connects to others in the web.

\section{Physical Activity and Everyday Life.}


When lay people are invited to talk about a given topic the matters that they bring forward for comment and discussion often appear to be disjointed - despite the fact that they are usually guided toward precise issues and questions. In terms of our data, for example, vandalism, dogs and the weather were referred to frequently by the group participants even though they were not specifically asked to comment on such matters. However, one of the virtues of focus group discussions is that participants feel free to voice and to exchange views and opinions about the things that concern them, rather than issues that are of concern to the investigators. In the words of Kitzinger (1995:299) focus groups 'reach the parts that other methods cannot reach'. In this light it is important for us to note exactly what ordinary people did speak about and how what they spoke of was connected.

Our first observation is that lay people view the area in which they live as a complex system of inter-related objects, activities and people. For example, it includes family members, neighbours, old people, children, and vandals; physical structures such as roads, rivers, and lakes as well as seats, shelters and cafés. It includes flora and fauna (especially dogs), the weather, the seasons, anti-social behaviour - to name just a few of the more frequently referenced items. In that context Figure 1 may be viewed, quite literally, as a snapshot of some of the common things that have to be engaged with and negotiated in everyday life - including roads, traffic, urban infrastructure and (most prominently) paramilitary activity.

This interconnectedness is particularly evident in the talk of the focus group participants and in this frame it is useful to examine the issue web in Figure 2. There one can see reference to a relatively limited number of physical activities - among which walking and cycling are the most frequently mentioned. (The bidirectional arcs or lines between walking and cycling indicate that the two things are often spoken of together). Also listed and connected in the speech of 
participants are various things that currently facilitate, or would be likely to facilitate increased physical activity. For example, it is evident that a sense of safety and the existence of green space (Nodes 7,8$)$ are both cited as facilitators of walking. Equally, things that are regarded as inhibitors of activity are listed and connected - the most marked of these is the negative effect of 'roads' and traffic on cycling (Nodes 14,15). The most prominent (largest) of the inhibiting nodes, however, is territoriality (Node 19) whilst the least important is 'winter/bad weather' (Node 16). Territoriality is in turn linked to vandalism, anti-social behaviour; a sense of safety and so on.

Figure 2 offers a visualization of issues raised in just one of the focus groups - FG12. Naturally, each group reflected the interests of its participants. In FG12 (a group of community based environmentalists) there was a good deal of talk about gardens and gardening - topics that simply did not appear in many other focus groups. Or to take another example, 'dogs' appear in group 12 conversation in a positive way; in some of the other groups they also appeared as an inhibitor. Traffic and roads are mentioned frequently in group 12, but make no appearance in, say, FG5 (a housing estate residents group). The essential point to note however is the interconnectedness of 'things' in the web, and that people talk about dogs, work, the weather, vandalism, infrastructure and so forth in a jumble. The world they reflect on is not a world that is firmly divided into leisure activities, economic activities, physical activities or any other category of action - the world comes as a piece. Note also that the talk is mainly of objects, structures and the behaviour of others - it is very rarely about personal beliefs, attitudes or motives. Indeed, being 'motivated' was mentioned in only 6 of the 14 groups and only in FG7 (a residents group) and FG8 (a mental health recovery group) was the word (or its cognates) used by respondents more than once. 
Our second observation, derived from reading across all of the transcripts, is that focus group participants tended to draw a distinction between being 'out and about' (primarily activity directed toward gaining a sense of social and personal wellbeing), and 'physical activity'. For example in FG2 (a mixed gender group of 'community leaders' that included ex-paramilitary and church members) the following interchanges arose about what the Greenway should be for (square brackets and italics indicate over-speaking; round brackets and breaks (...) reflect editing):

"I could be walking at an ambling pace just walking around feeling really eased and chilled out ... [it's good to get out and hear the birds chirping, it just lifts you, it lifts the spirits]... It's a raw deal thing rather [than can I run 50 miles] because a lot of people can't [do] physical activities... But the (Greenway) can provide a little oasis, a bit of tranquillity [but it's them things, and I know it's not your (i.e. the moderator's) remit, but it's not just physical activity it's something else].

This opinion was widespread (though not always stated quite so explicitly), so in what follows we explore the most important factors that were spoken of as facilitating or inhibiting activity in the wider (lay) sense. A summary and visualization of results is provided in the issue web in Figure 3, wherein we have concentrated on two categories of action: 'being out and about' in parks and open spaces, and 'being active' (consciously engaging in physical activity such as running, cycling and walking as an end in itself). Whilst most of the 'activity' that people referred to was outdoor activity (cycling, running, walking, rather than swimming) we kept such references separate from references to 'being out and about'. Nevertheless, there were some cases where the categories overlapped - as when people spoke of walking as both a casual, undefined activity and as a means of exercise. 
We can immediately deduce from the size of the nodes that 'being out' (Node 1) generated far more talk than did 'physical activity' (Node 2). We can also get a sense of the relative importance of the different factors that were mentioned across the 14 groups by looking at the size of the other nodes. Thus, Node 3 (physical infrastructure) and Node 10 (antisocial behaviour and vandalism) loom large, whilst Node 9 (existing commitments in employment and domestic life) is smaller. Once again it is important to note how things are connected and with what emphasis they are connected, and to that end the thickness of the connecting lines (arcs) between nodes provides an insight into the relative significance of that factor to one or other of our core variables. In what follows we discuss the nature of the other variables and their co-association.

The most frequently mentioned facilitator, by far, for being 'out and about' and being 'active' was physical infrastructure. The infrastructure that was most likely to encourage being out and about included well maintained paths, benches, seats, toilets, shelters and cafes though some also mentioned lights and lighting, and concert facilities were even discussed in one group. For 'being active' the emphasis was on things such as dedicated cycle paths and the provision of water fountains and changing rooms. Yet, whatever the purpose, there was a firm opinion that any such facilities would be (and had been in the past) vandalised and wrecked by young people - kids, teenagers, 'hoods'. (The thickness of the arcs between Nodes 10 and 3 reflect this association).

The next most important facilitator for being out was 'being safe' (Node 6 in Fig. 3) though this factor was thought to be of minimal importance for being active. A sense of safety and not being harassed by anti-social elements was mentioned in all but one of the groups (FG11, a SureStart fathers group), and it was given particular emphasis in FG2 and FG8. If we 
are not "going to be safe [we] might as well not bother going outside" suggested one of the participants in FG5. Following safety came 'good weather' (Node 4 in Fig. 3), and being out and about was seen as something to be undertaken mainly during the summer (references to which we combined with references to good weather). Good weather also figured strongly as a facilitator for being active. 'Other people' (Node 5) were frequently referenced as a facilitator for being out and for being active. 'Other people' could serve as a bulwark against anti-social elements and as a source of safety in general. In addition many participants thought that most kinds of activity ('dandering' as well as cycling) were social activities. "Nobody wants to go walking on their own", suggested a woman in FG7. Given the aims of the CCG planners it is encouraging to note that the provision of open green spaces (Node 7) was in itself seen as being good for being out and for being active - though it was associated with 'being out and about' 3 times more frequently than with being active. Finally, organizational infrastructure (Node 8) was seen as an important facilitator for participants - it featured as the second most important factor for being active. Organizational infrastructure included such things as organized walking groups, cycling and running clubs, or youth clubs and clubs for older people.

Against the facilitators, of course, were positioned inhibiting factors. The most prominent of these has already been mentioned; 'Vandalism' and 'Anti-Social Behavior' (Node 10 in Figure 3). Not surprisingly, many participants - walkers, cyclists and those who were unconcerned with 'physical activity' per se - referred to verbal insult and physical threats as a strong negative influence. Such behavior was often linked to younger people and groups of people who colonized and 'adopted' areas of existing parkland or entry points to existing parks and sought to assert sole user rights over communal areas. Thus, in FG12, for example, one of the participants recalled a recent incident in which he was told by a group of youths to leave the 
park because it was 'theirs'. "The whole park?" asked a fellow participant. "Yes, it was theirs and I was going to get a kicking".

Such colonization or territoriality has a distinctive variant in Belfast where most of the working class wards of the city are identified as either 'Catholic' and Nationalist, or 'Protestant' and Loyalist. Within the CCG the relevant Catholic/Nationalist area is known as 'The Strand' and in a number of focus groups it was recognized that residents of that area were unlikely to use the Greenway. "I can tell you if you're one of the Short Strand people there's no way that you're gonna walk the Greenway", [FG8]. In like manner it was reported in FG9 that, "The ones in the Strand wouldn't be inclined to use much stuff in East Belfast"; (though the wards of the Short Strand are actually in East Belfast). Some participants spoke of Catholic people being 'hunted out' of the local shopping centre and of being 'chased' from the district. The language is strong, but one can deduce from the images in Figure 1 that it not entirely unfounded. In Figure 3 we see that territoriality as a whole (Node 11) ranks quite strongly with vandalism and anti-social behavior as an independent inhibitor of going out and, to a lesser extent, of being active.

In the same way that good weather and the summer were spoken of as facilitating activity, bad weather and winter (Node 12 in Figure 3) were argued to be inhibitors of activity. Poor weather was referred to in all but 2 of the groups as a negative influence. In FG 9 (SureStart parents), for example, the opinion was that the greenway wouldn't be used much "because of our weather and it being outside". Bad weather just trumped the vagaries of urban infrastructure (kerbs, pavements, roads, dismal buildings) as an inhibitor for being out and about, though for physical activity urban infrastructure was seen as more of an impediment than poor weather. Finally, people mentioned the ways in which ordinary everyday demands of work, looking after children, shopping and so forth - inhibited the ability to either 'get out of 
the house' or to be active. It was the least influential of the inhibiting factors for being out and about (Node 9 in Figure 3), but ranked on a par with vandalism and territoriality for 'being active'.

\section{Discussion: Implications for policy and practice.}

Ever since the publication of the pioneering work of Morris, Heady, Raffle, et al (1953) epidemiologists have been aware of the positive benefits of physical exercise on human health. During the interim decades such benefits have been extended to cover aspects of mental as well as physical health (Scully, Kremer, Meade et al, 1998). By 2009 physical inactivity was being described as one of the "most important public health problems of the $21^{\text {st }}$ century" (Blair, 2009) and more recently as a 'pandemic' (Kohl, Craig, Lambert et al, 2012). The Global Burden of Disease Study (Lim, Flaxman, Danaei et al, 2012) concluded that physical inactivity ranked as the fifth leading cause of disease burden in Western Europe, and as one of the most important of modifiable risk factors; Kohl, Craig, Lambert et al (2012) and the WHO (2010:7) ranked inactivity as the fourth leading cause of death worldwide.

However, in Belfast - as in many other industrialized cities - only one third of adults engage in 'at least 30 minutes of moderate activity' for 5 days a week (SAPAS, 2010). The SAPAS data also point to varying levels of activity by gender, age, and socio-economic status - only one quarter of people in the lower socio-economic groups, one quarter of females and around $17 \%$ of people aged 50 and over meet the PA target. The SAPAS report speaks of a need to 'drive up' participation rates in the population as a whole and of how to improve motivation for sport. In that respect it is a document that reflects many prevailing ideas about (and aspirations for) PA and public health. This is clearly so where the authors equate PA with 'sport', and speak of low 
rates of PA as a problem that is in individuals - to be tackled by interventions that will improve 'motivation'.

Yet our data and our analyses suggest that low rates of PA are linked as much, if not more, to structures than to motives - that is, to things such as physical and organizational infrastructures and (beyond those) to political, civic (governmental), and territorial structures. This is not to suggest that structures (or elements of structures) are seen as determining the behaviour of individual actors or agents, but merely that ordinary people enrol 'structures' into their understanding of how PA is constrained, patterned and facilitated. Above all, perhaps the talk of our respondents underlines how improving the health of a community is not merely about focussing on regimes for fitness or 'getting people interested', but about improving policing and safety, urban design and traffic management and, in our case at least, challenging the nature of sectarian politics. In that sense it is clear that anti-social behaviour and 'territoriality' emerge every bit as much a health problem as a public order problem.

There are, of course, numerous cultural influences evident in the focus group discussions - references to 'weather' and its role in everyday activity is highly distinctive. Indeed, we have seen how important 'good' and 'bad' weather is to our Belfast residents, yet in many northern European societies the weather is rarely seen as a barrier to being outdoors. This is no doubt because 'weather' is, as Vannini, Waskul, et al (2012), and Ingold (2010) suggest, a product of both environmental forces and socio-cultural interpretation. It may also be the case that understandings of 'safety' are not simply a reflection of external environments and events, but woven into socio-cultural assessments of what is safe and unsafe (See, for example, Loukaitou-Sideris, 2006). 
On a conceptual level it is clear that many academic discussions of PA fail to take account of the nuances that lay people bring to that concept. We have distinguished between being 'out and about' and 'being active'. In terms of human physiology the two categories of action may well overlap - certainly at lower levels of PA. Yet for our respondents the two things are distinct. '[PA] is boring' said one of our FG9 participants rather bluntly. But going 'out and about', especially with others is attractive - so what is boring as an individual pursuit is seemingly more enticing and enriching in a social setting. Our respondents also conceive of 'activity' in a much wider frame than often appears in physical activity related policy documentation where it is often conflated with (competitive) 'sport' or spoken of as an individual pursuit (Sports Council for Northern Ireland, 1997; DHSSPS, 2006). Above all, being active is about not being sedentary - "The biggest challenge of all that is to get them off the sofa, that's the big one, you know" suggested a member of FG2. And somewhat encouragingly our participants tend to position 'activity' in the framework of everyday life and social engagement rather than in terms of regimes of physical fitness. In that respect our respondents might be said to point toward the use of the CCG as a therapeutic landscape (Gesler, 2005; Cattell,Dines, Gesler, Curtis, 2008) that would facilitate general 'wellbeing' as much as PA.

On a theoretical front, we would argue that the talk of our respondents reflects on central features of what sociologists have referred to as the structure/agency debate (Armstrong, 2014; Giddens, 1984). This is especially in so far as such talk so clearly connects individual 'behaviour' to civic, social, political and physical structures far more strongly than to motives and personal preferences. It is also useful to take note of the networking properties of our informants' talk and the ways in which informants seek to entangle a wide array of human and non-human agents into their discussion about being physically active. In that sense we can, 
perhaps, begin to see our informants as amateur Actor-Network-Theorists (Callon, 1986; Callon \& Law, 1982). Indeed, our issue webs reflect something very basic about lay understanding namely that everyday life is simply not segmented into 'domains' and 'levels' (as many health theorists would have it), but is seen as comprising a network of things, actors and influences such that it is the network or web that functions as 'agent', rather than any isolated individual(s).

In the field of health promotion we would argue that these (lay) interpretations resonate far more closely to what have been called social ecological models of health promotion (Sallis and Owen, 1997; Stokols, 1992) than they do to social cognition models. Indeed, as Burke, Joseph, Pasick et al, (2009) argue, social cognition models often regard the things that are highlighted by our respondents as merely 'contextual' and important only in so far as they have an effect on the attitudes and motives of individuals. Social ecology models, on the other hand, lay an emphasis on the interrelations between human beings and their environments and argue that health interventions have always to be multi-level - that is, intrapersonal, interpersonal, institutional and community directed (Golden \& Earp, 2012). Finally, it is evident that our respondents - again somewhat unwittingly - also point us toward a whole population approach to improving activity rates rather than approaches focussed on individuals or specific sub-groups within the community - develop the community, it would seem, and the benefits for individuals will follow.

\section{Conclusion.}

We have examined talk about physical activity in the context of issue webs, and suggested that our lay respondents can be seen as unwitting but firm advocates of what is 
referred to by health professionals as the social ecology approach. This is certainly the case in so far as our informants put an emphasis on 'structures' - material, organizational, social, economic and political - rather than on motivation and cognition, and see their behavior as intimately connected to those structures. Such a perspective offers a welcome corrective to suggestions that it is the individual human 'agent' that should be seen as the main or only target for reform. Indeed, there is a sense in which lay people offer us a novel vision of agency, by pointing to the network of things and issues that impinge on PA. As such, our data undoubtedly give empirical support to those who argue that PA policy must focus on, "populations and the complex interactions among the correlates of physical inactivity, rather than solely a behavioural science approach focusing on individuals" (Kohl, Craig, Lambert et al, 2012).

For lay people, it seems, living an active life is about safety and policing, social and family life, infrastructure and politics as much as it is to do with being motivated. So there is a sense in what our respondents are advocating also resonates with the call for 'Health in All' policy (Ståhl, Wismar, Ollila, et al 2006). However, it is not just an issue of seeing the problem of low rates of PA as 'multi-layered' or multi factorial, but of reconceptualising physical activity in lay terms - certainly away from a corpocentric emphasis on competitive 'sport' and individual achievement; even perhaps from 'physical activity' per se. Instead it's about being active in the sense of not being sedentary - "a better way of moving", as it was expressed in FG12. Consequently, most of our respondents sought activities in the presence of others and activity that slotted in to their everyday life - a world in which gardening is considered as good as gymnastics. 
Writing about the causes of ill-health, McKinlay (1994) argued that more advances could be made from the politicization of illness than from the modification of specific individual behaviours and that researchers and policy makers need to focus more 'upstream'. Exactly the same might be said of 'health'. More importantly, perhaps, it is clear that physical activity for ordinary people is related to a complex network of interconnected concerns and that it cannot be easily disengaged from such concerns - as our issue webs demonstrate. The way forward, it seems, is to accept the inherent complexity of the inactivity 'pandemic' and to focus on structure as much as behaviour and, above all, on the connections between the two.

\section{References:}

Ajzen, I. (1991). The theory of planned behavior. Organizational Behavior and Human Decision Processes, 50, 179-211.

Armstrong, D. (2014) Actors, patients and agency: a recent history. Sociology of Health and IIIness, 36,2, 163-174.

Becker, M. H. (1974). The health belief model and personal health behavior. Health Education Monographs, 2, 324-508.

Bandura, A. (1991). Social cognitive theory of self-regulation. Organizational Behavior and Human Decision Processes, 50, 248-287.

Blair, S. N. (2009). Physical inactivity: the biggest public health problem of the 21st century. British Journal of Sports Medicine, 2009, 43, 1-2.

Bryman, A. (2008). Social Research Methods. $3^{\text {rd }}$ ed. Oxford. Oxford University Press. 
Braun, V. \& Clarke, V., (2006). Using Thematic Analysis in Psychology. Qualitative Research in Psychology, 3, 77-101.

Burke, NJ, Joseph, G., Pasick, J, Barker, JC. (2009). Theorizing social context, Rethinking behavioural theory. Health Education \& Behavior, 36,55S-70S.

Callon, M. (1986). Some Elements of a Sociology of Translation: Domestication of the Scallops and the Fishermen of Saint Brieuc Bay. In J. Law (Ed.). Power, Action and Belief: a new Sociology of Knowledge? Sociological Review Monograph. London. Routledge and Kegan Paul. 32: 196233.

Callon, M. \& Law, J. (1982). "On Interests and their Transformation: Enrolment and CounterEnrolment." Social Studies of Science, 12: 615-625.

Catell, V., Dines, N., Gesler, W., Curtis, S. (2008). Mingling, observing and lingering: Everyday public spaces and their implications for well-being and social relations. Health \& Place, $14,544-$ 561.

Connswater Community Greenway (2013). http://www.communitygreenway.co.uk/ (Accessed November $6^{\text {th }}, 2013$ )

De Nooy, W., Mrvar, A., Batagelj, V. (2005). Exploratory Social Network Analysis with Pajek. Cambridge: Cambridge University Press.

Department of Health. (2011a). Start Active, Stay Active. A report on physical activity from the four home countries' Chief Medical Officers. London: Department of Health.

Department of Health, (2011b). UK Physical Activity Guidelines. Fact Sheet 4. Adults 19-64 years. https://www.gov.uk/government/publications/uk-physical-activity-guidelines (Accessed November $6^{\text {th }}, 2013, \&$ March $\left.30^{\text {th }}, 2014\right)$

DHSSPS (2006). Fit futures. Focus on Food, Activity and Young People. Belfast. Department of Health, Social Services and Public Safety. 
Ding, D. Sallis, JF, Conway, TL, Saelens, BE., Frank, LD, Cain, KL, Slymen, DJ. (2012). Interactive effects of built environment and psychosocial attributes on physical activity: a test of ecological models. Annals of Behavioral Medicine, 44, 3, 365-74.

Glanz, K., Rimer, B.K., Viswanath, K. (eds.) (2008). Health Behavior and Health Education. Theory, Research \& Practice. $4^{\text {th }}$ Ed. San Francisco. CA. Jossey-Bass. Chapter 2.

Gesler, W. (2005). Therapeutic landscapes: An evolving theme. Health \& Place, 11,295-297.

Giddens, A. (1984) The Constitution of Society. Cambridge.Polity.

Golden, S.D, \& Earp, J.A.L, (2012) Social Ecological Approaches to Individuals and Their Contexts: Twenty Years of Health Education \& Behavior Health Promotion Interventions. Health Education \& Behavior, 39(3) 364-372.

Ingold, T. (2010). Footprints through the weather-world: walking, breathing, knowing. Journal of the Royal Anthropological Institute (N.S.), S121-S139.

King, A.C., Stokols, D., Talen, E., Brassington, G.S., Killingsworth. R. (2002). Theoretical Approaches to the Promotion of Physical Activity. Forging a Transdisciplinary Paradigm. American Journal of Preventive Medicine, 23(2S), 15-25.

Kitzinger, J. (1995). Qualitative Research: Introducing focus groups, BMJ. 311, 299-302. Kohl, H.W, Craig, C.L., Lambert, E.V., Inoue, S., Alkandari, J.R., Leetongin, G., Kahlmeier, S. (2012). The pandemic of physical inactivity: global action for public health. Lancet, 380,294- 305.

Lim SS, Vos T, Flaxman AD, Danaei G, Shibuya K, Adair-Rohani H, et al. (2010). A comparative risk assessment of burden of disease and injury attributable to 67 risk factors and risk factor clusters in 21 regions, 1990-2010: a systematic analysis for the Global Burden of Disease Study 2010. Lancet, 2012, 380, 2224-60.

Loukaito-Sideris, A. (2006). Is it safe to walk? Journal of Planning Literature. 20, 3, 219-232. 
McKinlay, J.B. 1994 A case for refocusing healthcare upstream. The political economy of illness. In, P. Conrad and R. Kearn (Eds.) The sociology of health and illness. New York. St Martin's Press. Pp.509-530.

Morris, J., Heady, J.,Raffle, P., Roberts, C. \& Parks, J. (1953). Coronary heart disease and the physical activity of work. Lancet, 262(6795), 1053-1057.

Northern Ireland Multiple Deprivation Measure 2010. Northern Ireland Statistics and Research Agency, Belfast. Also at, http://www.nisra.gov.uk/deprivation/nimdm 2010.htm National Institute for Health \& Clinical Excellence, 2006. Four commonly used methods to increase physical activity. London: NIHCE.

Omran, A. R. (1971). The Epidemiologic Transition: A Theory of the Epidemiology of Population Change, The Milbank Memorial Fund Quarterly, 49, 4, 509-38.

Prior, L. (2014). 'Content Analysis'. In, P. Leavy. Ed. The Oxford Handbook of Qualitative Research Methods. Oxford Library of Psychology. New York. Oxford University Press. Pp.359-379.

SAPAS, 2010. The Northern Ireland Sport and Physical Activity Survey. Belfast. Sport Northern Ireland.

Sallis J.F, Owen N. (1997). Ecological models. In K. Glanz, F.M. Lewis., B.K. Rimer, (Eds.), Health behavior and health education: theory, research, and practice. San Francisco: Jossey Bass, Pp.403-24.

Scully, D., Kremer, J. Meade, M, Graham, R, Dudgeon, K. (1998). Physical exercise and psychological wellbeing: a critical review. British Journal of Sports Medicine, 32, 111-12. Stokols D. (1992). Establishing and Maintining healthy environments. Towards a social ecology of health promotion. American Psychologist, 47, 1, 6-22.

Sports Council Northern Ireland. (1997). Starting Well, Staying Involved and Striving for Excellence. Belfast. SCNI. 
Ståhl, T., Wismar, M., Ollila, E., Lahtinen, E. Leppo, K.(Eds.) (2006). Health in All Policies.

Prospects and potentials. Finland: Ministry of Social Affairs and Health, for the European Observatory on Health Systems and Policies.

Tully, M., Hunter, R, MCaneney, H, Cupples, M., Donnelly, M., Ellis, G., Hutchinson, G., Prior, .L. Stevenson, M. Kee, F. (2013). Physical activity and the rejuvenation of Connswater: protocol for a natural experiment investigating the impact of urban regeneration on public health. $B M C$ Public Health, 13:774. doi:10.1186/1471-2458-13-774.

WHO (2010). Global Recommendations on Physical Activity for Health. Geneva. WHO.

WHO (2013). Global Data Base. https://apps.who.int/infobase/Indicators.aspx. (Accessed, November 6th, 2013, \& March $\left.31^{\text {st }}, 2014\right)$.

Vannini, P., Waskul,D., Gottschalk, S. Ellis-Newstead, T. (2012). Making Sense of the Weather:

Dwelling and Weathering on Canada's Rain Coast. Space and Culture, 15, 4, 361-380. 
Click here to download high resolution image

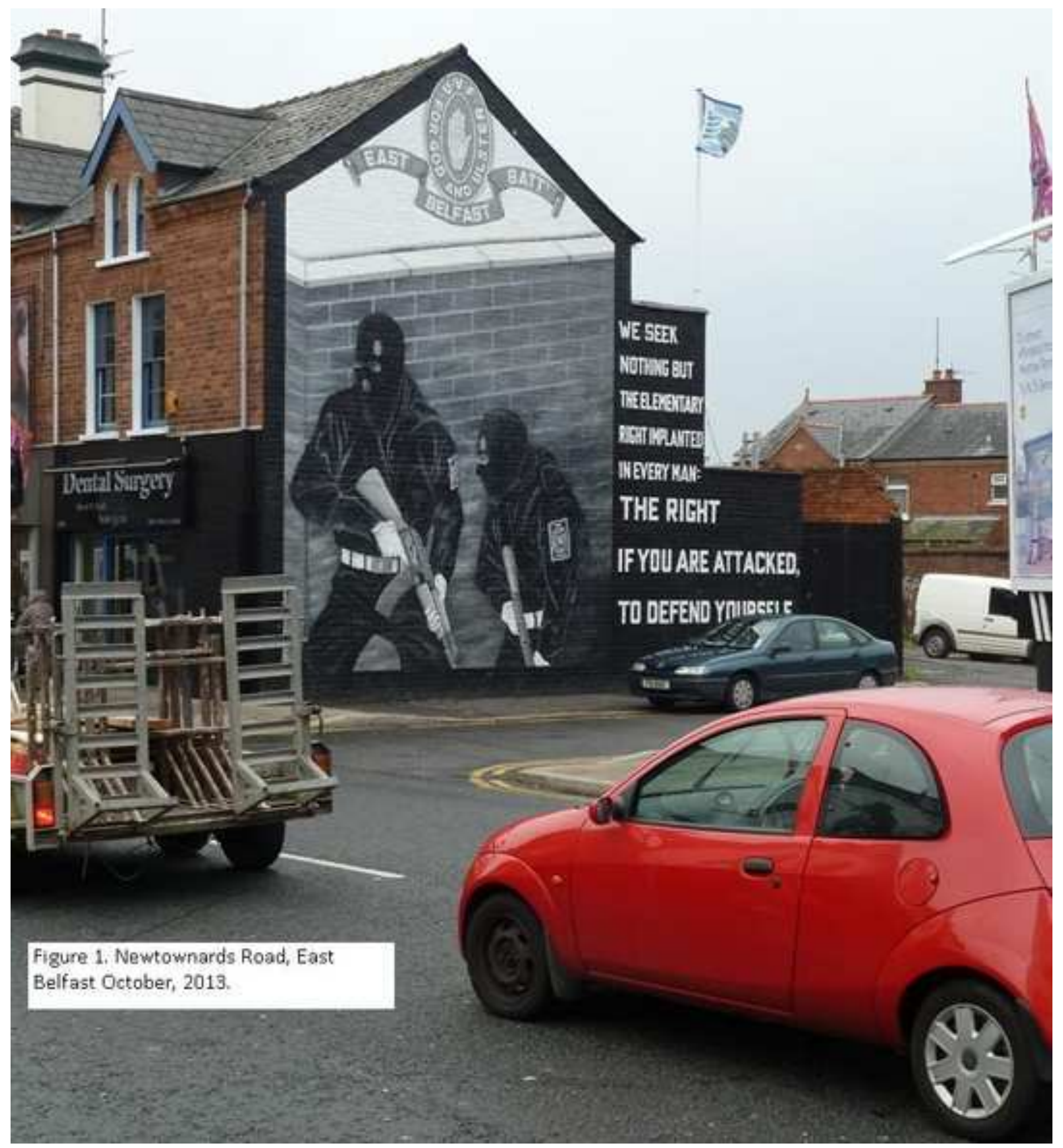


Figure 2. Issue Web for Focus Group 12.

Nodes are proportional in size to frequency of reference. Arcs (line thickness) proportional to strength of coassociation between references.

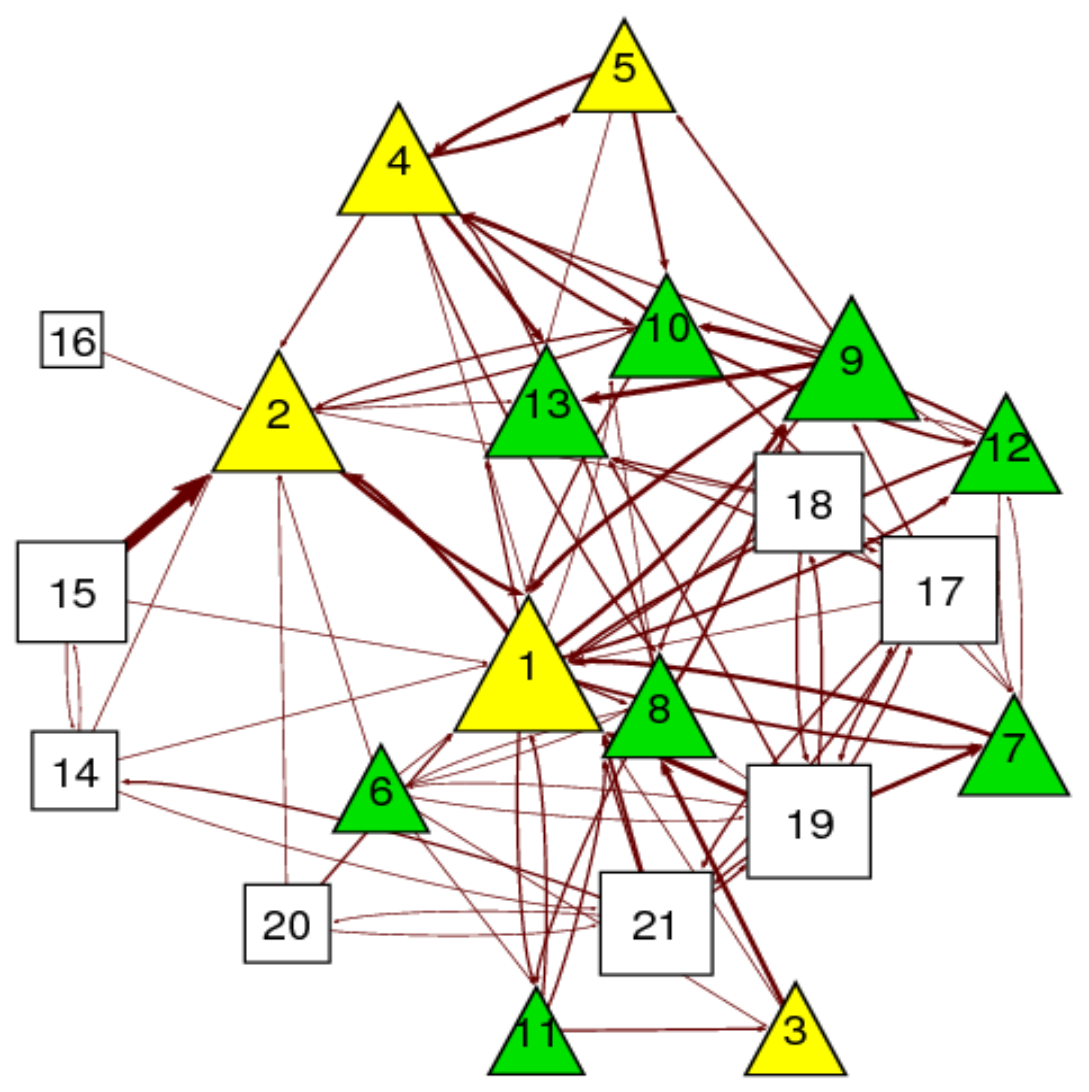

Index of Activities: 1 = Walking, 2= Cycling, 3 = Running, 4 = Gardening, 5= Hobbies.

Index of Facilitators: 6= Summer, 7 = Safety, 8 =Green Space, 9 =Gardens, $10=$ Infrastructure for leisure, $11=$ Dogs, 12 = Being with the Family, $13=$ Sense of Community.

Index of Inhibitors: 14 =Traffic, 15 = Roads, 16 = Winter, 17 = Vandals, 18 = Anti-social behaviour, 19 = Territoriality, $20=$ The demands of everyday life including work, $21=$ Urban Infrastructure. 
Figure 3. How being 'out and about' and 'active' are co-associated with key variables in 14 focus group discussions.

Nodes are proportional in size to frequency of reference. Arcs (line thickness) proportional to strength of coassociation between references.

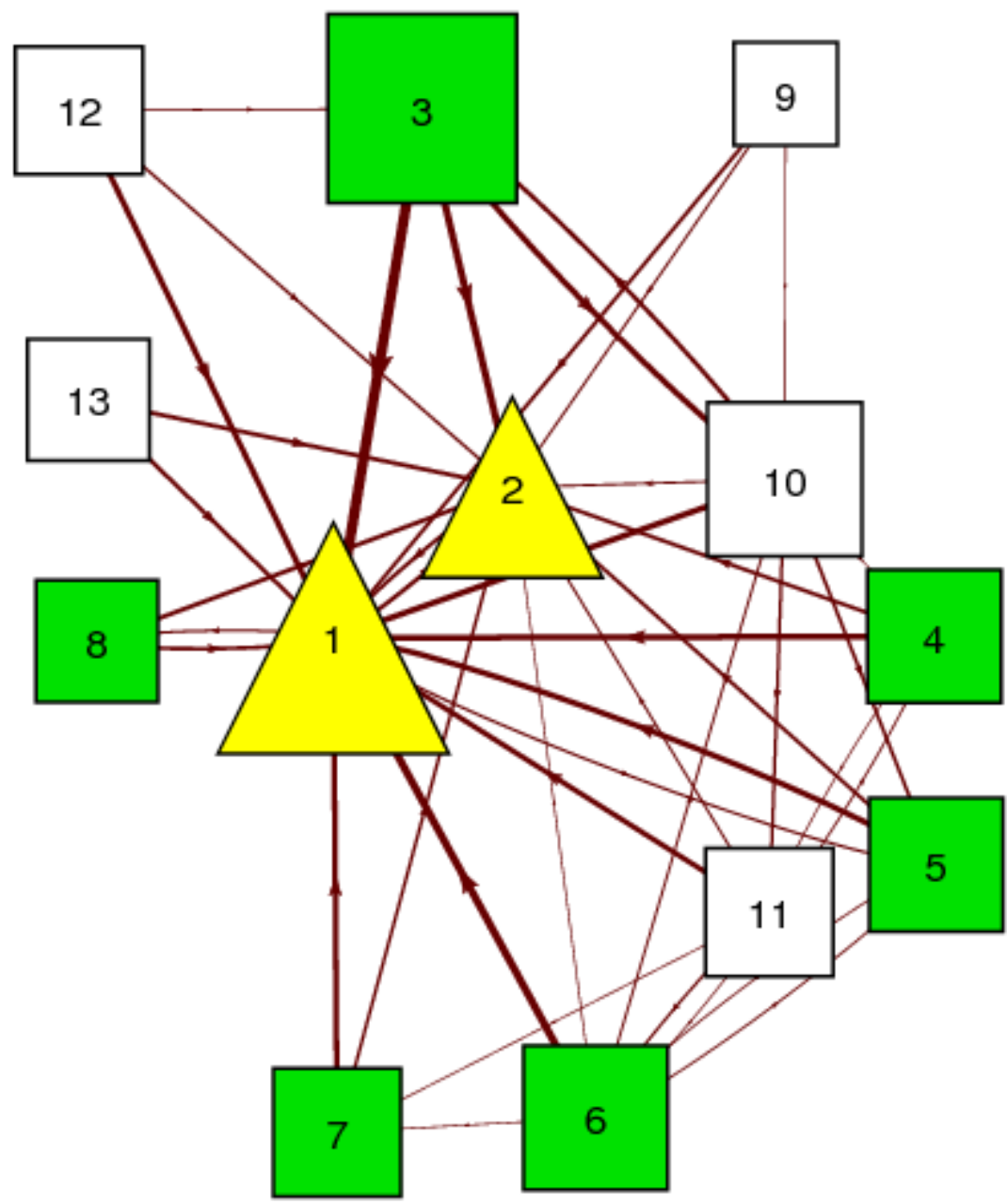

Index of Activities: 1 = Being out and about, 2= Being Active.

Index of Facilitators: 3= Physical Infrastructure, $4=$ Good weather, $5=$ Other People, $6=$ Being Safe, $7=$ Greenery and Open Space, 8 = Organizational Infrastructure.

Index of Inhibitors: 9 = Current demands of work and daily life, $10=$ Vandalism \& Anti-social behaviour, $11=$ Territoriality, 12 = Bad Weather, 13 = Urban Infrastructure. 

${ }^{*}$ Ethics approval/Statement EA not required

Ethical approval for the study was provided by OREC (Northern Ireland). Reference, 09/NIR02/66 